\title{
難治性皮膚潰瘍治療に適した軟膏基剤の開発とその臨床評価に関する研究
}

\author{
重山昌人

\section{Preparation of a Gel-Forming Ointment Base Applicable to the Recovery Stage of Bedsore and Clinical Evaluation of a Treatment Method with Different Ointment Bases Suitable to each Stage of Bedsore}

\author{
Masato SHIGEYAMA \\ Department of Pharmacy, Takayama Red Cross Hospital, 3-11 Tenman-cho, \\ Takayama City 506-8550, Japan
}

(Received November 7, 2003)

\begin{abstract}
An ointment base for better treatment of bedsores was developed to improve the release rate of minocycline hydrochloride $(\mathrm{MH})$ and the water absorption capacity using various types of hydrophobic to hydrophilic ointment bases. The effect of purified lanolin (PL) on the release behavior of $\mathrm{MH}$ from a hydrophilic ointment (HO) base was the primary focus. It was found that the drug release rate from the ointment base was modified according to the method of preparation of the ointment base and the type of cyclodextrins admixed. The physicochemical properties, such as viscosity, elution volume, and water absorption, of the ointment base were also modified by those factors. To develop an ointment formulation suitable for the recovery stages of bedsores, including the proliferation period of granulation and the formative period of epidermis, the physicochemical properties of Macrogol ointment containing various hydrophilic polymers, which have gel-forming ability, were tested. A novel ointment base suitable for the treatment in the recovery stage of bedsores was developed using hydrophobically modified hydroxypropyl methylcellulose (HM-HPMC). Considerably sustained release of $\mathrm{MH}$ ( $\mathrm{T}_{50}$ of 170 at a min) was attained with a macrogol ointment mixed with HM-HPMC and Carbopol formulation ratio of $3: 7$. We clinically evaluated the effectiveness of bedsore treatment by applying different ointment bases to patients with different stages of bedsores.
\end{abstract}

Key words_ - gel-forming ointment; bedsore; carbopol; hydrophobically modified hydroxypropyl methylcellulose; controlled release

\section{1. はじめに}

皮膚は諸藏器の中でも常に外気に曝されており, 抵抗性も強く容易に壊死に陥るものではない。しか し，これが破壊された場合には，早急にこれを補修 しようとする創傷治癒過程が働く，しかし，創傷が 大きすぎる場合や深すぎる場合，あるいは治癒を妨 げる循環傷害, 栄養障害, 細菌感染がある場合に は，自然治癒過程がうまく進まずに難治性皮膚潰瘍 となる。 ${ }^{1-4)}$ 裖瘡，難治性皮膚潰瘍の治療は，高齢 化社会を迎えて, 長期病臥する老人が増えつつある 現代の医療で, 益々重要な問題となってきている.

高山赤十字病院薬剤部（テ506-8550 高山市天満町 311)

e-mail: eroshige@ @idanet.ne.jp

*本総説は, 平成 15 年度日本薬学会東海支部学術奨励 賞の受賞を記念して記述したものである.
そのため, 裖瘡の院内治療における合理的な製剤設 計法の開発が待たれている.

従来の裖瘡治療は，皮膚潰瘍の病期を検討せず, 画一的に保存的治療として線維素溶解䤄素剂 5 ,6) 抗潰瘍剂, ${ }^{7,8)}$ 殺菌目的として局所への抗生剂 や, ${ }^{9-13)}$ ポピドンヨード・シュガー等 ${ }^{14,15)}$ が使用さ れてきた。しかし，これら薬剤単独の使用では優れ た治療成績を得ることができなかった。 また, 裷瘡 の各病期に最適な軟膏基剤が市販されていないのが 現状である。そこで筆者は, 裖瘡の各病期に対して 最適な軟膏基剂を設計する課題に取り組み, 効果的 な軟膏基剤を開発し，その臨床的有用性を見出し た. 以下にこの病期分類に基づいた軟膏基剤の開発

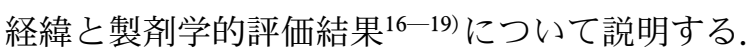




\section{2. 薬物放出挙動及び吸水性に及ぼす軟膏基剤の} 影響

2-1. 各種軟膏基剤からの塩酸ミノサイクリン （MH）の放出挙動軟膏基剤に配合された薬物 が治療効果を発揮するためには，基剂から放出され た薬物が皮膚深部に浸透しなければならない。した がって，基剂からの薬物放出性は皮膚吸収に影響を 与える重要な因子の 1 つである。 そこで, Franz 型 拡散セルを用いて, 軟膏基剤からの $\mathrm{MH}$ の放出挙 動を試験液に蒸留水を用いて検討した. 6 種類の性 質の異なる基剤から MH の放出を測定した結果が Fig. 1 (a)である.

次に, Fig. 1 (b) に示すように, 各種軟膏基剤か らの $\mathrm{MH}$ の放出量を時間の平方根に対してプロッ トするとマクロゴール軟膏（MO）を除いていずれ も良好な直線関係が得られた。この現象について軟 膏からの薬物の放出が拡散律速であるとする W. I. Higuchi の Eq. ${ }^{20,21)}$ を適用した. すなわち, 薬物が 基剂に完全に溶解しておりしかも放出量が 30\%以 下のときは, 放出量は Eq. (3)で表される.すなわ ち, 時間 $t$ における薬物の放出量 : $Q$, 基剤中の初 濃度 : $C_{0}$, 基剤中の薬物の拡散定数 : $D$ とすると

$$
Q=2 C_{0} \sqrt{D t / \pi}
$$

一方, 薬物が基剤中において懸濁系での基剤から
の薬物放出に関しては, T. Higuchi ${ }^{22)}$ の考察があ り, 薬物濃度 : $A$, 薬物の基剂外層への溶解度 : $C_{\mathrm{s}}$ とすると Eq. (4)で表さ

$$
Q=\sqrt{2 A D C_{\mathrm{s}} t}
$$

れる.

$2 C_{0} \sqrt{D / \pi}$ 及び $\sqrt{2 A D C_{\mathrm{s}} t}$ をかけの放出速度定数： $k$ とすると, Eqs. (3) 及び(4) は Eq. (5)で表される.

$$
Q=\sqrt{k t}
$$

Equation (5) に従って Fig. 1 (b) の直線の傾きより 求めた各種軟膏基剤からの MH のみかけの放出速 度定数（ $k$ ) Table 1 に示す. Fig. $1(\mathrm{~b})$ 及び Table 1 から明らかなように, MH の基剤からの放 出性に優れたものから順に MO > 親水軟膏 $(\mathrm{HO})$ $>$ 吸水軟膏 $(\mathrm{AO})>$ 親水ワセリン $(\mathrm{HP})>$ 白色ワ セリン (WP)>プラスチベース（PO）であった. MO は, 実験開始後短時間で薬物を放出してしまう ため実験は 90 分までとしたが，この時間内では極 めて良好な放出が認められた.

今回の結果では, 親水性の大きい順に放出が大き い傾向が認められた，すなわち，乳剂性基剤でも外 相が水である $\mathrm{HO}$ が最も放出がよく, W/O 型で水 相を有する $\mathrm{AO}$ は $\mathrm{HO}$ と $\mathrm{HP}$ の中間程度の放出が みられた。 また, 疎水性基剂である WP, PO は放 出が悪いことが判明した。 次に, 試験液をより生体 (a)

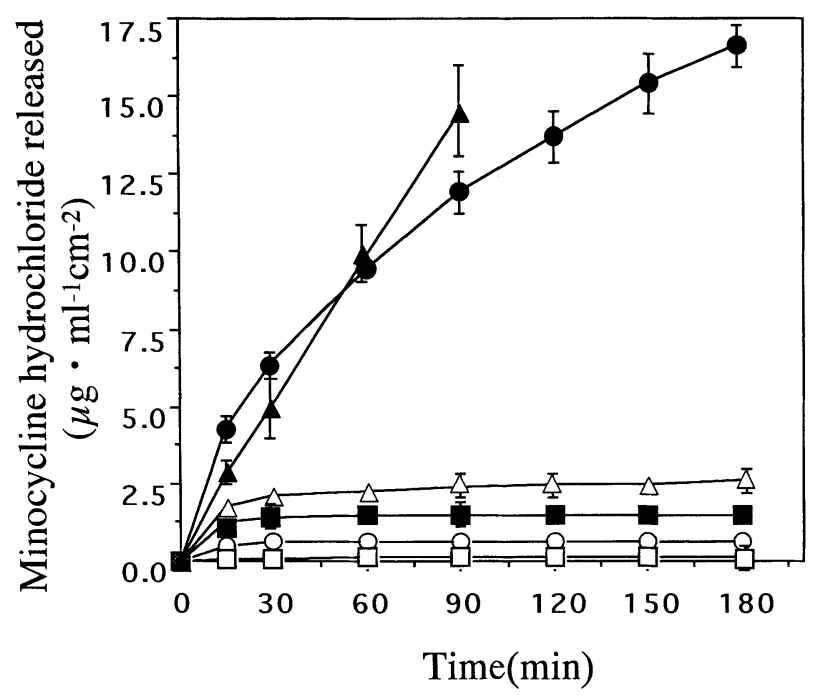

(b)

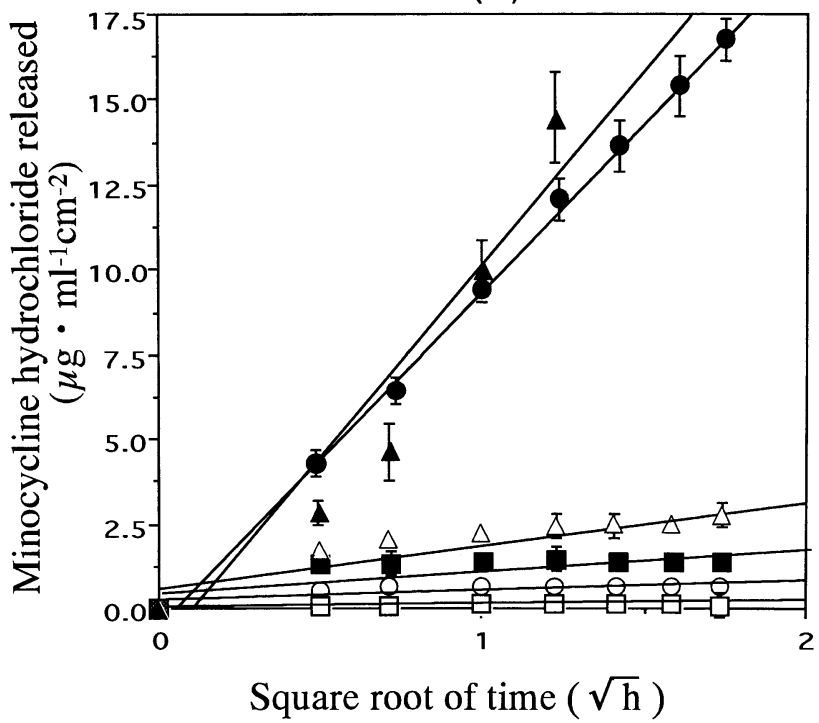

Fig. 1. Release of Minocycline Hydrochloride (a) and Drug Release Plots according to Higuchi's Equation (b) from Various Ointment Bases in Distilled Water

$\bigcirc$ : white petrolatum (WP), $\bigcirc$ : hydrophilic ointment (HO), $\square:$ petrolatum polyethylene ointment (PO), $\boldsymbol{\square}:$ hydrophilic petrolatum (HP), $\triangle:$ absorptive ointment (AO), $\boldsymbol{\Delta}$ : macrogol ointment (MO). Measurement temperature: $37^{\circ} \mathrm{C}$. Data represent the mean \pm S.E. of three experiments. 
Table 1. Apparent Release Rate Constant of Minocycline Hydrochloride from Various Ointments (Distilled Water and Lactated Ringer's Injection)

\begin{tabular}{ccc}
\hline \hline Ointment & $k \mathrm{w}$ & $k \mathrm{l}$ \\
\hline WP & $0.29 \pm 0.057$ & $0.22 \pm 0.071$ \\
HO & $9.86 \pm 0.459$ & $6.10 \pm 0.502$ \\
PO & $0.09 \pm 0.021$ & $0.04 \pm 0.018$ \\
HP & $0.65 \pm 0.106$ & $0.50 \pm 0.072$ \\
AO & $1.28 \pm 0.268$ & $1.02 \pm 0.212$ \\
\hline
\end{tabular}

$k \mathrm{w}$ : apparent release rate constant $\left(\mu \mathrm{g} \cdot \mathrm{ml}^{-1} \mathrm{~cm}^{-2} h^{-1 / 2}\right)$ in water. $k \mathrm{l}$ : apparent release rate constant $\left(\mu \mathrm{g} \cdot \mathrm{ml}^{-1} \mathrm{~cm}^{-2} h^{-1 / 2}\right)$ in lactated Ringer's injection. Data represent the mean \pm S.E. of three experiments.

に近い状態にするため，蒸留水を乳酸リンゲル液に 変更して上記と同様の試験を行った.

各軟膏基剤からの MH の放出性の結果を Fig. 2 に示す。 Table 1 に示すように，MH の各基剤から の放出速度定数は，試験液が蒸留水の場合と同様順 位に変更はなかった。しかし，全体に放出性が低い 傾向が認められた。MH の各基剂からの放出速度 定数は, 試験液が蒸留水の場合よりも乳酸リンゲル 液の方が全体に放出性が低い傾向が認められた。こ の現象を明らかにするため, 拡散セルを用いて薬物 溶解液から，セルロース膜を透して試験液中に溶出 される MH を定量した。その結果，3 時間内にお いては乳酸リンゲル液よりも蒸留水を試験液に用い た方がセルロースメンブラン膜から MH の溶出性 が高いことが判明し，この溶出性の差が Franz 型 拡散セルを用いて放出試験を行ったときの放出性の 差の原因と考えられた。そこで，蒸留水及び乳酸リ ンゲル液中の $\mathrm{HM}$ の拡散係数を求めた.

本実験の拡散式は Eqs. (6) 及び(7)で表される.

$$
V \cdot \mathrm{dc} / \mathrm{dt}=D \cdot S\left(C_{0}-C\right) / h
$$

$$
\ln \left\{C_{0} /\left(C_{0}-C\right)\right\}=D / h \cdot S / V \cdot t
$$

ここで, $C_{0}=$ 基剤中の初濃度, $C=$ 薬物放出後の 濃度, $V=$ 容量, $S=$ セルロースメンブラン膜の面 積, $h=$ セルロースメンブラン膜の厚さである.

Equation (7) で示されるように, $t$ と $\ln \left\{C_{0} /\left(C_{0}-\right.\right.$ $C) ＼mathrm{~ と の 間 に 直 線 関 係 か ゙ 成 立 す る の て ゙ ， そ の 直 線 ~}$ の傾きから拡散係数 $D$ を求めることができる．そ の結果，軟膏のマトリックスのポアーに満たされた 乳酸リンゲル液 $\left(0.124 \times 10^{-6} \mathrm{~cm}^{2} / \mathrm{sec}\right)$ よりも，蒸 留水 $\left(0.627 \times 10^{-6} \mathrm{~cm}^{2} / \mathrm{sec}\right)$ での薬物拡散係数が高 いことが判明した。したがって，軟膏マトリックス

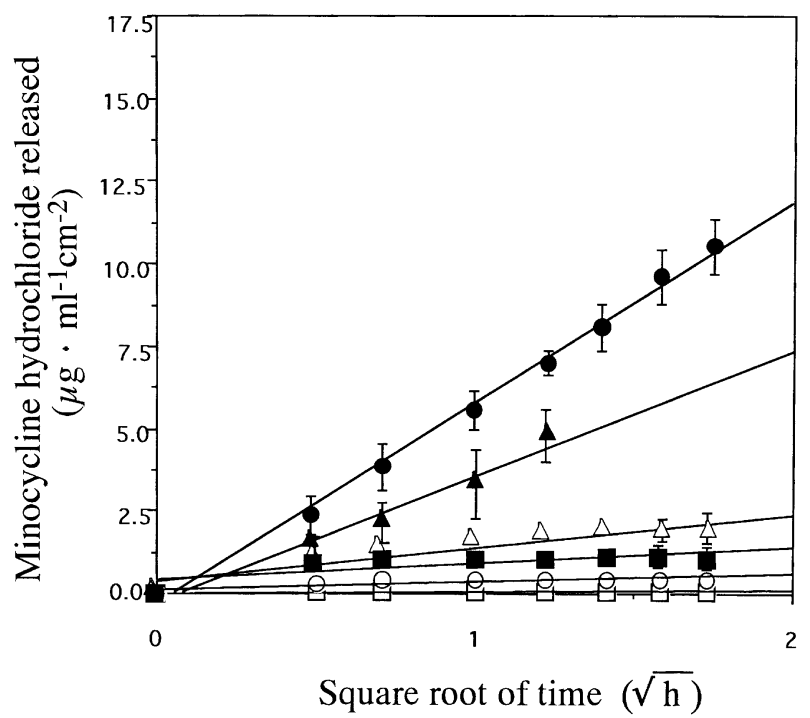

Fig. 2. Release of Minocycline Hydrochloride from Various Ointment Bases in Lactated Ringer's Solution

$\bigcirc$ : white petrolatum (WP), $\mathbf{0}$ : hydrophilic ointment (HO), $\square$ : petrolatum polyethylene ointment (PO), $\mathbf{\square}$ : hydrophilic petrolatum (HP), $\triangle:$ absorptive ointment (AO), $\boldsymbol{\Delta}:$ macrogol ointment (MO) . Measurement temperature: $37^{\circ} \mathrm{C}$. Data represent the mean \pm S.E. of three experiments.

中の水路網（水性チャネル）における MH の拡散 速度が乳酸リンゲル液に比べて蒸留水中の方が速 $<，$ 薬物放出速度も高くなつたものと思われる.

2-2. 薬物放出挙動に及ぼす精製ラノリンの影響 当院において，炎症性皮膚疾患にヨードカリ軟膏が 使用されているが，軟膏中の精製ラノリン（PL） は患部の膿瘍を吸水する目的で配合されている。 そ こで，薬物放出性が優れていた HO に PL を各濃度 で添加することにより，MH の放出に及ぼす影響 について検討を行った. Figure 3 に示すように，各 種軟膏基剤からの $\mathrm{MH}$ の放出量を時間の平方根に 対してプロットすると，PL の濃度の違いにより薬 物の放出性が異なることが判明した。つまり， Table 2 に示すごとく, PL を各濃度で添加すると 放出速度定数が高くなり，HO70\%PL30\%の混合基 剤が最も薬物放出速度定数が高くなることが判明し た。この結果は, PL を 30\% HO に添加することに より吸水性が高まり，基剂中の水溶性物質の溶出が 促進されることにより水性チャネルが構成されて薬 物放出性が促進されたと考察した。また，軟膏基剤 からの薬物放出速度定数と軟膏基剤の粘度との間に は負の相関関係があり，軟膏基剤の粘度が低いほど 薬物放出速度定数が高いことが判明した. 


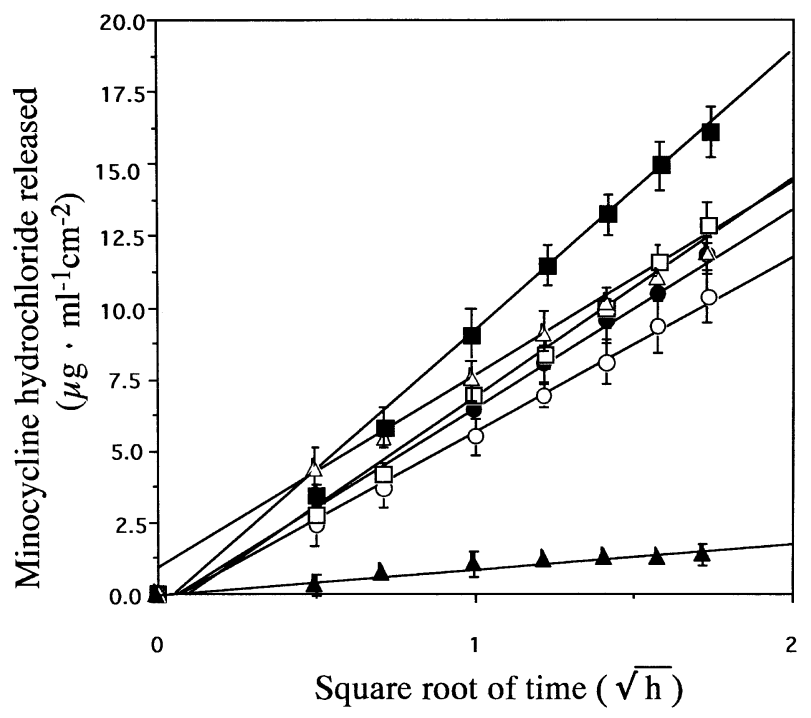

Fig. 3. Effects of Purified Lanolin Concentration on the Release Behavior of Minocycline Hydrochloride from Hydrophilic Ointment in Distilled Water

O : hydrophilic ointment 100\% (HO100), 0 : hydrophilic ointment 90\%: purified lanolin10\% (HO90 : PL10), $\square$ : hydrophilic ointment $80 \%$ : purified lanolin20\% (HO80 : PL20), $\mathbf{\square}$ : hydrophilic ointment 70\%: purified lanolin 30\% (HO70 : PL30), $\triangle$ : hydrophilic ointment 60\%: purified lanolin 40\% (HO60 : PL40), $\boldsymbol{\Delta}$ : purified lanolin 100\% (PL100). Measurement temperature: $37^{\circ} \mathrm{C}$. Data represent the mean \pm S.E. of three experiments.

Table 2. Effect of Composition of Ointment Base on Its Apparent Viscosity and the Release Rate of Minocycline Hydrochloride from the Ointment

\begin{tabular}{ccc}
\hline \hline $\mathrm{HO}: \mathrm{PL}^{a)}$ & $k^{b)}$ & $V^{c)}$ \\
\hline $100: 0$ & $6.10 \pm 0.502$ & $1.121 \pm 0.161$ \\
$90: 10$ & $6.95 \pm 0.372$ & $1.085 \pm 0.079$ \\
$80: 20$ & $7.59 \pm 0.488$ & $0.995 \pm 0.163$ \\
$70: 30$ & $9.72 \pm 0.528$ & $0.926 \pm 0.106$ \\
$60: 40$ & $6.73 \pm 0.543$ & $1.110 \pm 0.183$ \\
$0: 100$ & $0.83 \pm 0.121$ & $1.651 \pm 0.353$ \\
\hline
\end{tabular}

a) HO: hydrophilic ointment, PL: purified lanolin. b) $k$ : apparent release rate constant $\left(\mu \mathrm{g} \cdot \mathrm{ml}^{-1} \mathrm{~cm}^{-2} h^{-1 / 2}\right)$ in lactated Ringer's injection. c) $V$ : apparent viscosity $(\mathrm{Pa} \cdot \mathrm{s})$. Data represent the mean \pm S.E. of three experiments.

\section{3. 裖瘡治療により効果のあるシクロデキストリ} ン添加塩酸ミノサイクリン軟膏の物理化学的特性の 改良

3-1. 薬物放出性 HO に PL を各濃度で添加 すると, 放出速度定数が高くなり，HO70\% PL30\% の混合基剤が最も薬物放出速度定数が高く, かつ吸 水性がよい基剤であることを報告した。したがっ て，今回の実験では基剤は HO70：PL30 の処方を 用い $\mathrm{MH}$ の放出挙動に及ぼす各種 $\mathrm{CyD}$ 及びデキス

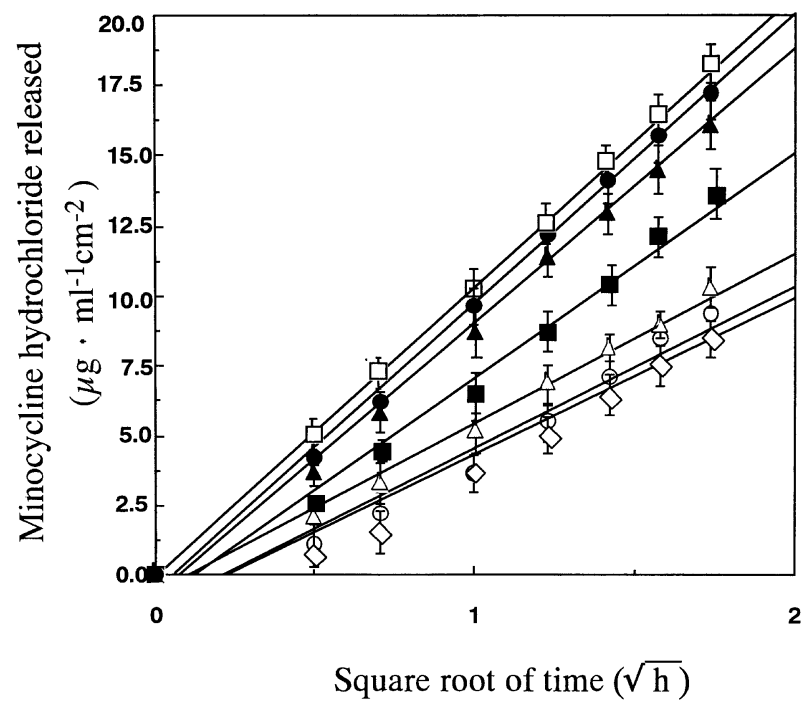

Fig. 4. Higuchi Plots of Release Profiles of Minocycline Hydrochloride from Ointment Containing Various Cyclodextrins Prepared by Fusing Method

- : $\alpha-\mathrm{CyD}, \square: \beta-\mathrm{CyD}, \boldsymbol{\square}: \gamma-\mathrm{CyD}, \triangle: \mathrm{DM}-\beta-\mathrm{CyD}, \mathrm{O}: \mathrm{TM}-\beta-$ $\mathrm{CyD}, \diamond:$ dextrin, $\boldsymbol{\Delta}:$ none. Data represent the mean \pm S.E. of three experiments.

トリンの影響について検討を行つた. Figure 4 に示 すように，各種 $\mathrm{CyD}$ 添加軟膏基剂からの MH の放 出量を時間の平方根に対してプロットするといずれ も良好な直線関係が得られた。この現象について軟 膏からの薬物の放出が拡散律速であるとする T. Higuchi のEq.22) を適用した. Figure 4 の直線の傾 きより求めた各種 $\mathrm{CyD}$ 及びデキストリン添加軟膏 基剂からの $\mathrm{MH}$ のかけの放出速度定数（k) を Table 3 に示す. Figure 4 及び Table 3 から明らか なように，基剤に各種 $\mathrm{CyD}$ 及びデキストリンを 5 \%濃度で添加すると, 各種 $\mathrm{CyD}$ 添加軟膏基剤から の $\mathrm{MH}$ の放出速度定数は, デキストリン $<\mathrm{TM}-\beta-$ $\mathrm{CyD}<\mathrm{DM}-\beta-\mathrm{CyD}<\gamma-\mathrm{CyD}<$ None $<\alpha-\mathrm{CyD}<\beta-$ $\mathrm{CyD}$ の順に増大した。すなわち，軟膏基剤に $\beta$ $\mathrm{CyD}(p<0.05)$ を添加することにより， MH の放 出促進, $\gamma-\mathrm{CyD}(p<0.05), \mathrm{DM}-\beta-\mathrm{CyD}(p<0.01)$, $\mathrm{TM}-\beta-\mathrm{CyD} \quad(p<0.05)$ ，デキストリン $(p<0.05)$ で放出抑制効果が認められた。 ところが, 軟膏基剂 にCyD を添加し物理混合した場合, 薬物放出性に は影響を及ぼさず，薬物放出速度定数は低下した。

$\mathrm{CyD}$ 類と軟膏基剂を物理混合した場合と溶融分散 した場合とでは，薬物放出挙動に差異が生じた。す なわち, $\alpha-\mathrm{CyD}(p<0.01), \beta-\mathrm{CyD}(p<0.05)$ 添加 軟膏基剤を溶融分散した場合，物理混合した場合よ 
Table 3. Apparent Release Rate Constant and Viscosity of MH Ointment Containing Various Additives

\begin{tabular}{lcccc}
\hline \hline \multicolumn{1}{c}{ Additives } & \multicolumn{1}{c}{$k^{a)}$} & $k^{b)}$ & $V^{c)}$ & Solubility $(\mathrm{g} / 100 \mathrm{ml})$ \\
\hline None & $9.72 \pm 0.53$ & $9.38 \pm 0.49$ & $0.93 \pm 0.11$ & - \\
$\alpha$-CyD & $10.16 \pm 0.22$ & $7.12 \pm 0.18^{d)}$ & $0.90 \pm 0.18$ & 14.5 \\
$\beta$-CyD & $10.93 \pm 0.31^{e)}$ & $5.22 \pm 0.35^{d)}$ & $0.89 \pm 0.11$ & 2.0 \\
$\gamma$-CyD & $8.05 \pm 0.49^{e)}$ & $7.93 \pm 0.39$ & $1.02 \pm 0.22$ & 23.2 \\
DM- $\beta$-CyD & $6.06 \pm 0.59^{f)}$ & $6.19 \pm 0.46$ & $1.09 \pm 0.16$ & 57 \\
TM- $\beta$-CyD & $5.79 \pm 0.67^{e)}$ & $5.86 \pm 0.62$ & $1.18 \pm 0.13$ & 31 \\
Dextrin & $5.37 \pm 0.69^{e)}$ & $5.31 \pm 0.67$ & $1.66 \pm 0.23$ & - \\
\hline
\end{tabular}

a) $k$, apparent release rate constant (fused mixture) $\left.\left(\mu \mathrm{g} \cdot \mathrm{ml}^{-1} \mathrm{~cm}^{-2} h^{-1 / 2}\right) . b\right) k$, apparent release rate constant (physical mixture) $(\mu \mathrm{g}$. $\mathrm{ml}^{-1} \mathrm{~cm}^{-2} h^{-1 / 2}$.c) $V$, viscosity $(\mathrm{Pa} \cdot \mathrm{s})$ of fused mixture. Composition of ointment base: HO 70: PL 30. Data represent the mean \pm S.E. of three experiments. $d$ ) $p<0.01$ vs. fused mixture. e) $p<0.05$ vs. none. f) $p<0.01$ vs. none.

りはるかに放出性が高くなった， $\gamma-\mathrm{CyD}$ ではその 差が少なく, $\mathrm{DM}-\beta-\mathrm{CyD}, \mathrm{TM}-\beta-\mathrm{CyD}$ でもその差 が少ないことが判明した.

3-2. 物理化学的特性 (吸水量 · 溶出量 · みかけ の粘度）＼cjkstart各種 $\mathrm{CyD}$ を軟膏基剤に添加すること により，粘度・溶出量・吸水量を変化させ，これら の物理化学的性質と薬物放出性とは相関性があるこ とが判明した。軟膏基剤に各種 CyD を添加し, 溶 融分散したときの軟膏基剤の粘度を Table 3 に示 す。軟膏基剤に各種 $\mathrm{CyD}$ を添加することにより, 軟膏基剤の粘度に影響を与えることが判明した。 $\mathrm{CyD}$ 類添加軟膏基剂を溶融分散し，レオメーター を用いて粘度を測定した。その結果，軟膏基剤を溶 融分散することによりみかけの粘性に変化が生じ, $\mathrm{CyD}$ 類添加軟膏基剤のみかけの粘度は, $\beta-\mathrm{CyD}<\alpha$ $-\mathrm{CyD}<\boldsymbol{\gamma}-\mathrm{CyD}<\mathrm{DM}-\beta-\mathrm{CyD}<\mathrm{TM}-\beta-\mathrm{CyD}<$ デキス トリンとなった．Fig. 5 に示すように，みかけの粘 度が高くなると薬物放出速度定数が低下する結果と なった。軟膏基剤に, $\mathrm{DM}-\beta-\mathrm{CyD} \cdot \mathrm{TM}-\beta-\mathrm{CyD}$ ・ デキストリンを添加すると薬物放出性が抑制され た. その理由として, 軟膏基剤の粘度が高くなるこ ととマトリックス基剂からの薬物拡散係数が低下す るためと考えられた。 それに反して， $\beta-\mathrm{CyD}$ を軟 膏基剤に添加することにより, 粘度が低下し薬物放 出性が促進された。 $37^{\circ} \mathrm{C}$ の水溶液中で $\mathrm{MH}$ の溶解 度を測定した結果, $\beta-\mathrm{CyD}$ を添加してもその溶解 度には変化がなかった。.この現象は, 薬物放出速度 定数を促進させるために軟膏基剤中に添加した $\beta-$ $\mathrm{CyD}$ が, 薬物と包接化されている可能性がないこ とを示している。溶出試験中の $\beta-\mathrm{CyD}$ 及び $\mathrm{DM}-\beta$ $-\mathrm{CyD}$ 添加軟膏基剂の溶融分散時及び物理混合時の

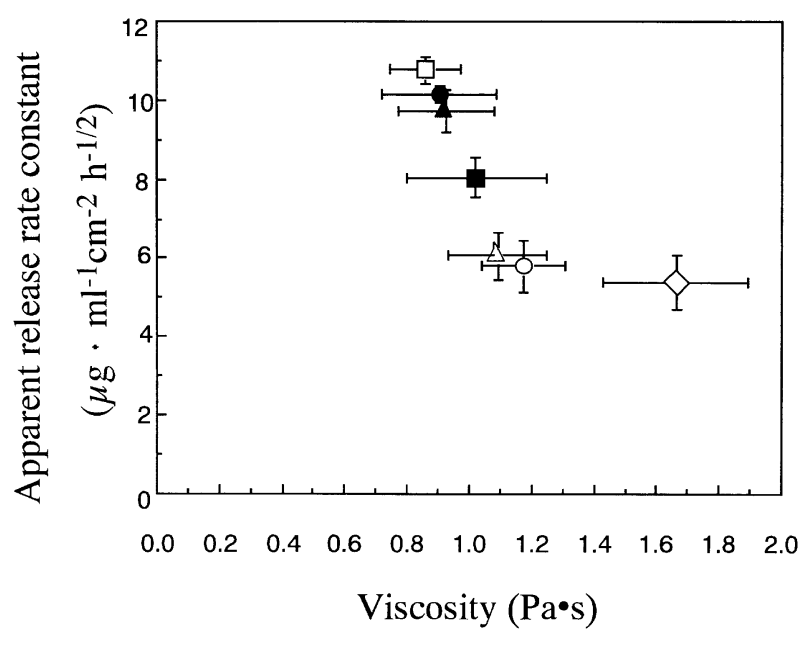

Fig. 5. Relationship between Viscosity and Release Rate $: \alpha-\mathrm{CyD}, \square: \beta-\mathrm{CyD}, \boldsymbol{\square}: \gamma-\mathrm{CyD}, \Delta: \mathrm{DM}-\beta-\mathrm{CyD}, \mathrm{O}: \mathrm{TM}-\beta-$ $\mathrm{CyD}, \diamond:$ dextrin, $\boldsymbol{\Delta}:$ none. Data represent the mean \pm S.E. of three experiments.

基剤自体の溶出量と吸水量について検討を行つた. その結果, Fig. 6 (a) に示すように DM- $\beta-C y D$ 添加 軟膏基剂は, 溶融分散時及び物理混合時において軟 膏基剤自体の溶出量も吸水量もそれほど変化は認め られなかった。 それに対して Fig. 6(b)に示すよう に $\beta-\mathrm{CyD}$ 添加軟膏基剤の場合, 溶融分散時及び物 理混合時において, 吸水量に関してはほとんど差が ないものの, 軟膏基剤自体の溶出量が溶融分散した 場合と物理混合した場合とでは大きな差が生じた。 以前の研究から, 軟膏基剤の溶出性は精製ラノリン が $30 \%$ の処方時最も大きいことが証明されてい る。軟膏基剤の吸水性は, PL の濃度が高くなる 程, 一様の増加を示した. しかし, PL の割合が 30 \%以上になると，溶出量は低下した。したがっ， 軟亳基剂中の PL が吸水することにより軟膏基剤の 


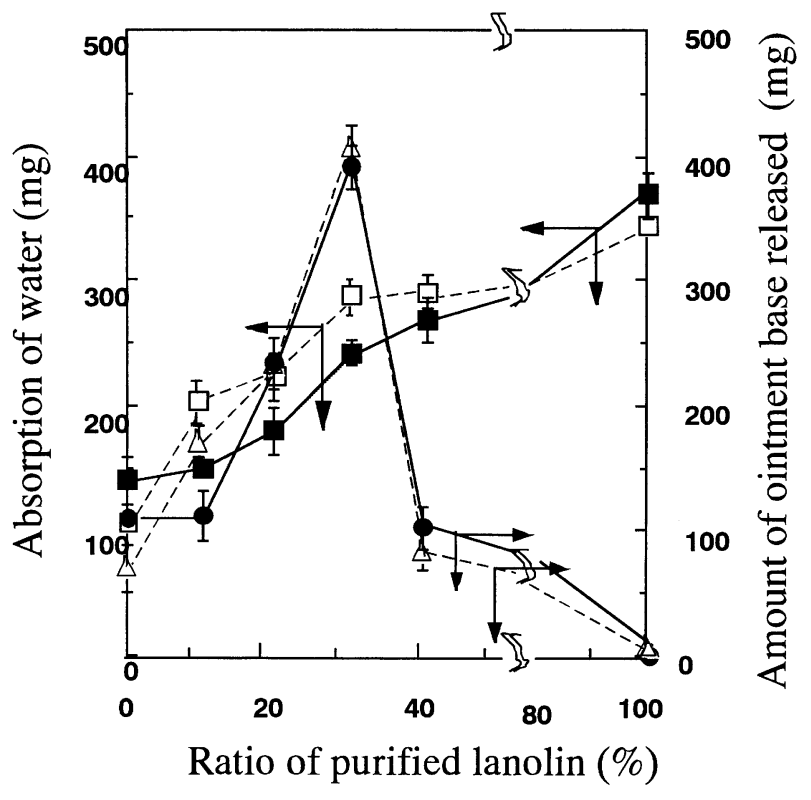

Fig. 6(a). Effect of Concentration of Purified Lanolin on Absorption of Water and Amount of Released Ointment Base with DM- $\beta-\mathrm{CyD}$

$\checkmark$ : DM- $\beta-\mathrm{CyD}, \boldsymbol{\square}: \mathrm{DM}-\beta-\mathrm{CyD}$ (- fused mixture), $\triangle: \mathrm{DM}-\beta-$ CyD, $\square: \mathrm{DM}-\beta-\mathrm{CyD}$ (--- physical mixture). Data represent the mean \pm S.E. of three experiments.

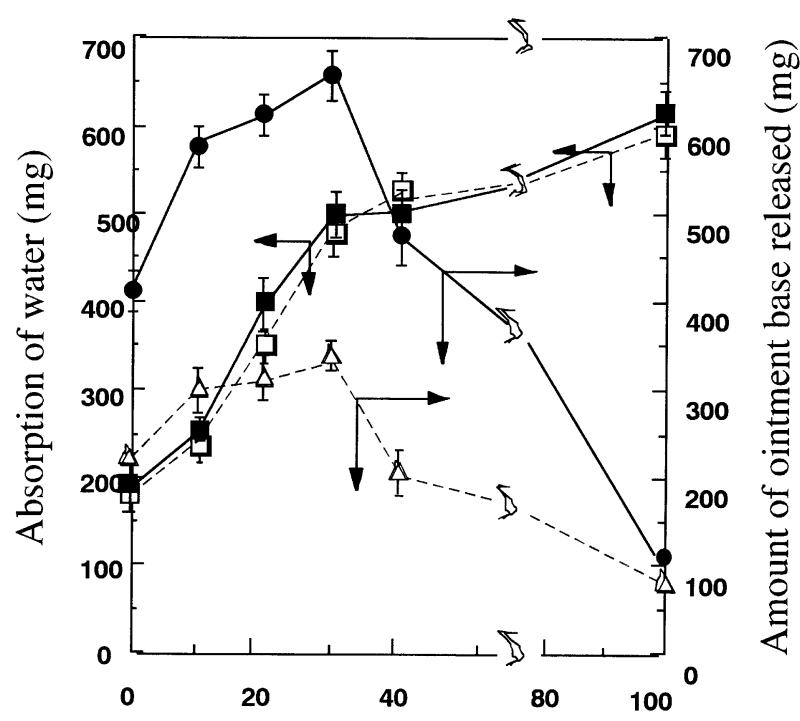

Ratio of purified lanolin (\%)

Fig. 6(b). Effect of Concentration of Purified Lanolin on Absorption of Water and Amount of Released Ointment Base with $\beta-\mathrm{CyD}$

$\boldsymbol{0}: \beta-\mathrm{CyD}, \boldsymbol{\square}: \beta-\mathrm{CyD}$ (- fused mixture), $\Delta: \beta-\mathrm{CyD}, \square: \beta-\mathrm{CyD}$ (--- physical mixture). Data represent the mean \pm S.E. of three experiments.

マトリックス構造は膨潤し, 軟膏基剤中の水溶性物 質の溶出が薬物の拡散と同様促進されたものと考え られた．軟膏基剤の調製方法の区別をなくせば，軟
亳基剂中の PL 濃度が増加すれば軟膏基剤の吸水量 は増加する。軟膏基剤に $30 \% \mathrm{PL}$ と $\beta-\mathrm{CyD}$ を添加 し, 溶融分散することにより粘度を低下させ, 溶出 量・吸水量を増加させ, 裖瘡患部に対して刺激性を 抑えさらに水洗いできやすくなるため, 裖瘡治療に は最適な軟膏基剂であると考えられる。

3-3. 軟膏基剤の構造各種 $\mathrm{CyD}$ を軟膏基剤 に添加したときの軟膏基剤の構造変化を起こす物理 化学的性質のメカニズムを, 光学顕微鏡を用いて明 らかにした. Figure 7 に示すように軟膏基剤に $\alpha-$ $\mathrm{CyD}, \beta-\mathrm{CyD}$ を添加し溶融分散して調製すると乳滴 が観察され，薬物放出速度定数が高くなつた。 それ に反して, $\mathrm{DM}-\beta-\mathrm{CyD}, \mathrm{TM}-\beta-\mathrm{CyD}$ では構造変化 はわずかであり, 乳滴は観察されなかった。水溶性 色素アマランス及び疎水性色素ズダン III により着 色検査した結果, この液滴は油滴であることが判明 した。したがって， $\alpha-\mathrm{CyD}, \beta-\mathrm{CyD}$ を軟膏基剤に 添加し溶融分散するとエマルジョン構造が不安定化 し, 油滴が合一することが判明した.この構造変化 の結果, 軟膏の粘性が低下したものと思われる. 油 滴ができる状態を図式的に表示したものが Fig. 8 である. HO70\%：PL30\%を混合したものを基剤と して，それに， $\alpha-\mathrm{CyD}, \beta-\mathrm{CyD}$ を添加し溶融分散 すると油滴ができ，それに反して DM- $\beta-\mathrm{CyD}, \mathrm{TM}$ $-\beta-\mathrm{CyD}$ を添加し溶融分散しても油滴ができなかっ た。また，各種 CyD 及びデキストリンをそれぞれ 軟膏基剤に添加し, 物理混合した場合はいずれの基 剂も油滴が観察されなかった.

したがって, 軟膏基剤中に乳化状態で溶解してい た $\mathrm{HCO}-60$ が, $\alpha-\mathrm{CyD}, \beta-\mathrm{CyD}$ との間で相互作用 が起きたことが示唆された。これは, 油滴の界面張 力を下げることにより, 油滴を遊離させることに導 いたと考えられる，ところが， DM- $\beta-\mathrm{CyD}, \mathrm{TM}-\beta$ $-\mathrm{CyD}$ は水溶性が高い $\mathrm{CyD}$ である。 $\mathrm{DM}-\beta-\mathrm{CyD}$, $\mathrm{TM}-\beta-\mathrm{CyD}$ は油滴の表面よりはどちらかといえ ば，水相側に選択的に分布していると考えられる. デキストリンを軟膏基剤に添加しても, 物理化学的 性質を変化させることができなかつた，その理由と して, デキストリンは分子内に空洞がなく, 界面活 性剂と相互作用を起こすことがないためと考えられ た. Figure 9(a)に示すように, $\beta-\mathrm{CyD}$ と DM- $\beta-$ $\mathrm{CyD}$ を $\mathrm{HCO}-60$ 水溶液に混和すると, 界面張力が 変化することが確認された。 DM- $\beta-\mathrm{CyD}$ を各濃度 


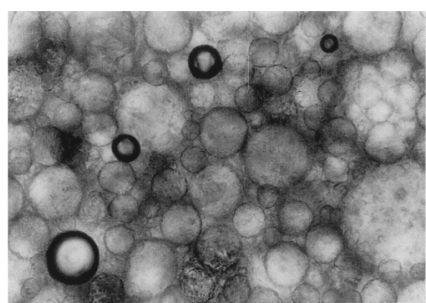

$\alpha$-CyD $\overline{20 \mu m}$

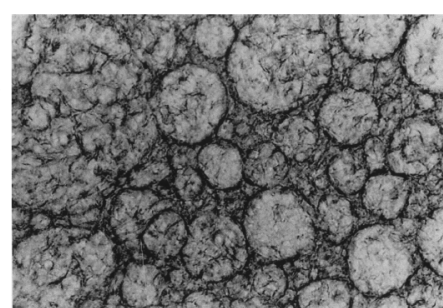

$\beta-C y D \quad \overline{20 \mu \mathrm{m}}$

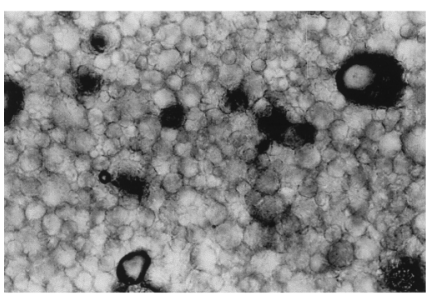

$\overline{20 \mu \mathrm{m}}$

$r-C y D$

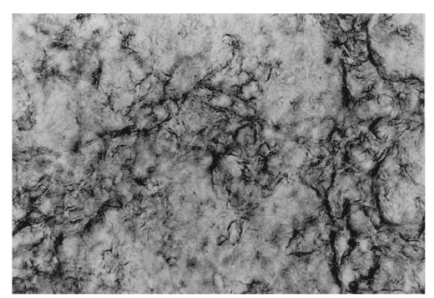

$\overline{20 \mu \mathrm{m}}$

$\mathrm{DM}-\beta-\mathrm{CyD}$

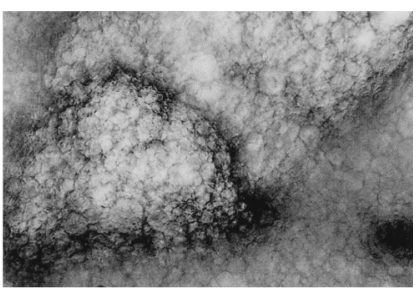

$\overline{20 \mu \mathrm{m}}$

$\mathrm{TM}-\beta-\mathrm{CyD}$

Fig. 7. Photomicrograph of Ointments

Fused mixture: $5 \%$ additives, $1 \%$ MH. Ointment base: HO70 : PL30.

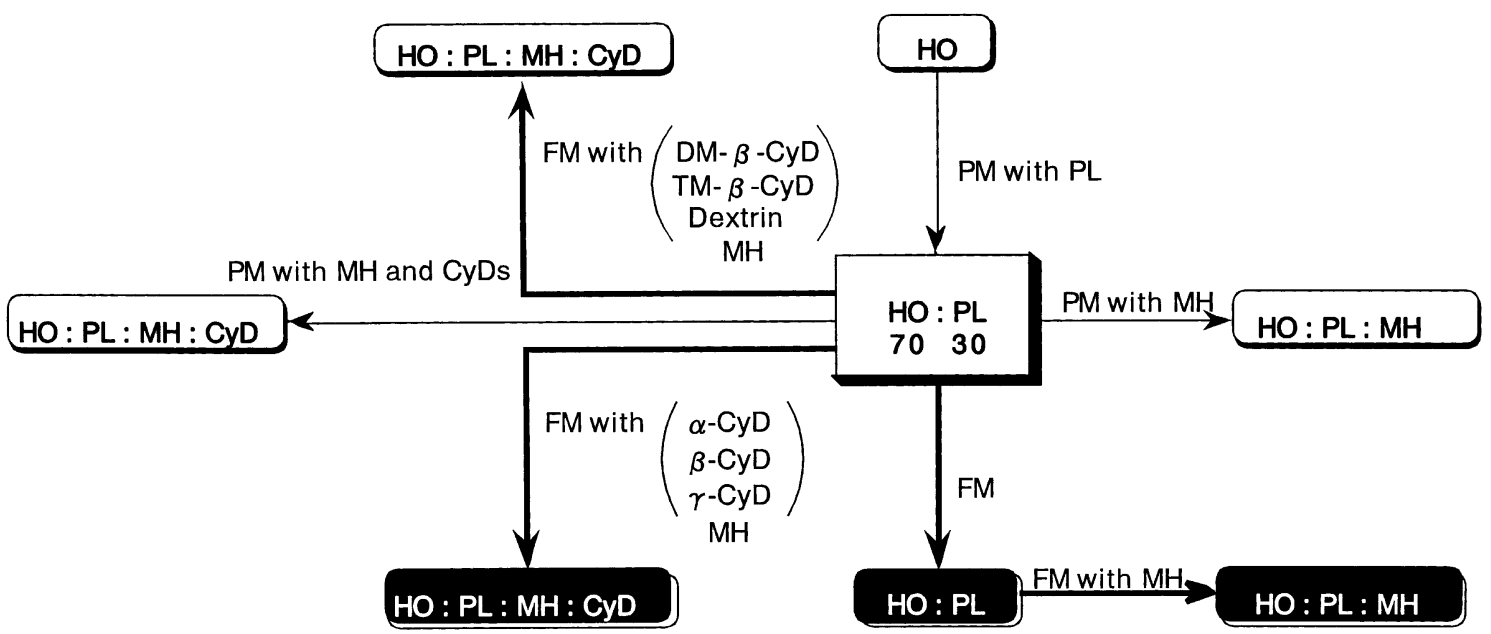

HO: Hydrophilic Ointment

PL : Purified Lanolin

$\mathrm{MH}$ : Minocycline Hydrochloride

FM : Fused Mixture

PM : Physical Mixture

: Oil droplets were detected

: Oil droplets were not detected

Fig. 8. Schematic Diagram of Structural Conversion of Ointment

で HCO-60 水溶液に添加していくと，その溶液の 界面張力に対しては少しの影響しか与えなかった. ところが $\beta-\mathrm{CyD}$ の濃度を増加させると, 界面張力 も増加する傾向が認められた，この現象は，軟膏基
剂中の $\mathrm{HCO}-60$ と $\beta-\mathrm{CyD}$ が相互作用を引き起こし ていることが推測された。したがって, $\beta-\mathrm{CyD}$ を 軟膏基剂に添加し溶融分散して調製すると, 油滴が 合一化することにより粘度が低下し，その結果とし 
(a)

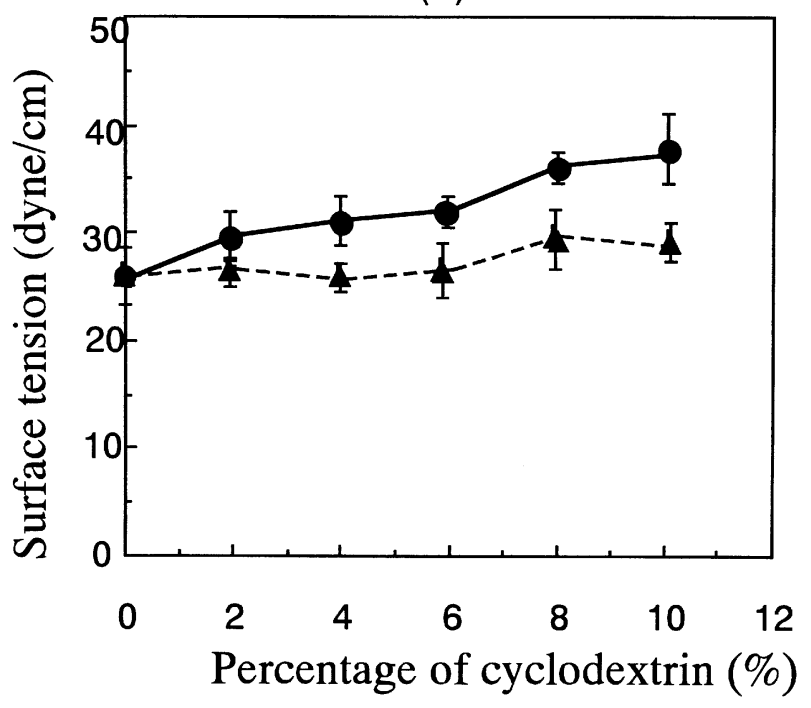

Fig. 9(a). Effect of Concentration of Cyclodextrin on Surface Tension of $10 \%$ Concentration of $\mathrm{HCO}-60$

$\boldsymbol{0}: \beta-\mathrm{CyD}, \boldsymbol{\Delta}: \mathrm{DM}-\beta-\mathrm{CyD}$. Data represent the mean \pm S.E. of three experiments.

(b)

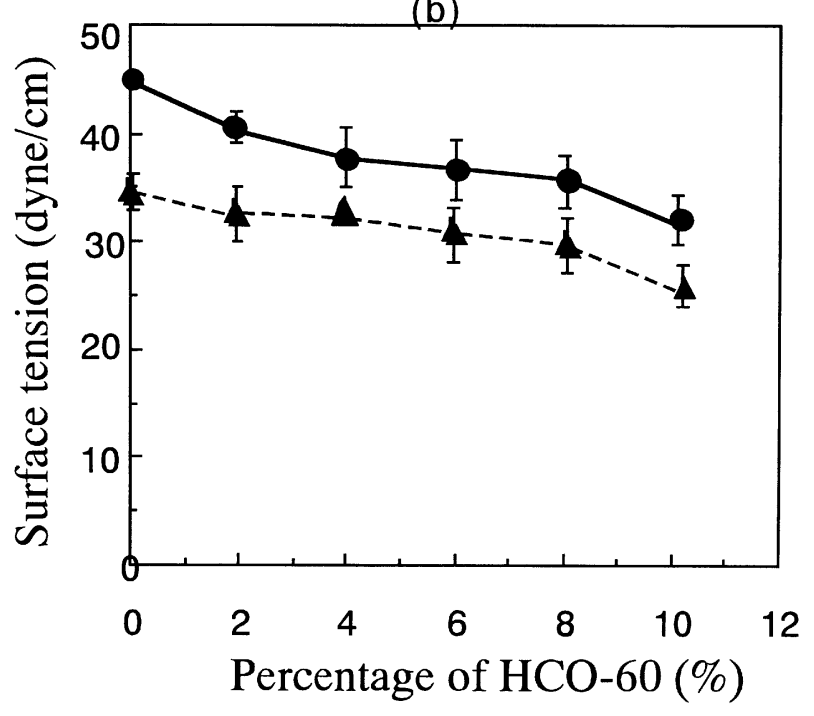

Fig. 9(b). Effect of Concentration of HCO-60 on Surface Tension of $5 \%$ Concentration of Cyclodextrins

$\boldsymbol{0}: \beta-\mathrm{CyD}, \boldsymbol{\Delta}: \mathrm{DM}-\beta-\mathrm{CyD}$. Data represent the mean \pm S.E. of three experiments.

て薬物放出速度定数が増加したものと考えられた.

TM- $\beta-$ CyD 及び DM- $\beta-$ CyD は Fig. 9 (b) に示すよ うに， $\beta-\mathrm{CyD} よ り も$ 界面活性作用が高いため油滴 が合一されず， $\beta-\mathrm{CyD}$ が軟膏基剤中に含有してい る場合よりも，TM- $\beta-\mathrm{CyD}$ 及び $\mathrm{DM}-\beta-\mathrm{CyD}$ が軟 膏基剤中に含有している場合の方が粘度が高い值を 示した.

\section{3-4. 軟亳基剤中の安定性評価 Figure 10 は,} 軟膏基剂を室温及び冷所で保存後, 光学顕微鏡を用 いて軟膏基剤の構造変化を観察した。 室温で保存し た場合油滴の合一化が若干認められた。 それに対し て, 冷所で 1 週間保存した場合エマルジョンの構造 上の変化は認められなかった。 Figure 11 は, $\beta-$ $\mathrm{CyD}$ 添加軟膏基剂を溶融分散し冷所及び室温保存 後, 薬物の放出性の変化を調べるため, 薬物放出速 度定数の変化について検討を行つた結果である. 冷 所で 7 日間, 室温で 3 日間までは, 薬物放出速度定 数の低下は認められず安定であることが判明した。

したがって， $\beta-\mathrm{CyD} に よ り$ 再構築されたエマルジ ヨン系は，実用上の安定性は保証できることが明ら かとなった，その理由として，臨床の場で使用され る軟膏剂は, 病院薬剤部で用時調製し供給している からである.

4. 回復期の裖瘡治療に適した部分疎水化ヒドロ キシプロピルメチルセルロース（HM-HPMC）及 びカーボポール (CP) 添加塩酸ミノサイクリン軟 亳の設計

4-1. HM-HPMC 添加 MO 基剤の特性裖創 部の浸出液を吸水保持する機能を検討するため, 各 種 HM-HPMC 添加 MO 基剂の吸水力試験を重量 法にて行った. MO に各種 HM-HPMC を $5 \%$ 添加 し, 蒸留水を $0.5 \%$ 添加後混合した軟膏基剤の $1 \mathrm{~g}$ 中当たりの吸水量を測定した。 なお，蒸留水を 0.5 \%添加した理由は少量の水分を軟膏基剤に添加する ことにより水溶性高分子のゲル化が促進され, 薬物 放出性をさらに延長させることができたためであ る. その結果, Fig. 12 に示すように, HM-HPMC の中で唯一水溶液に溶解する $\mathrm{T}-5059$ を使用した軟 膏基剂が, 各種 HM-HPMC 添加 MO 基剤中最も 吸水性が高かった。しかし, 既に報告した HPC 添 加 $\mathrm{MO}$ 基剤と比較すると, LA 基の置換度が最も大 きい $\mathrm{T}-5062$ を使用した軟膏基剤でも同程度の吸水 量を示した。 各種 HM-HPMC を MO 基剤に添加 し, その基剤を溶融分散後, カードテンションメー ターを用いて硬度を測定した. その結果, Fig.13に 示すように HPC 添加 MO 基剤よりも各種疎水化 HPMC 添加 MO 基剤の方が硬度が低く, 軟膏基剤 としては適度な硬度であることが判明した，MOに 各種 HM-HPMC を 5\%添加することによる, 薬物 の放出特性の変化を調べた. モデル薬物の MH の 


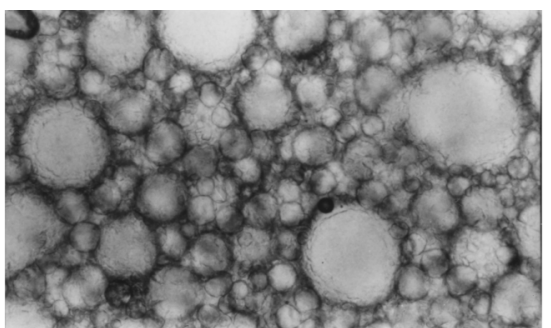

(a) before storage
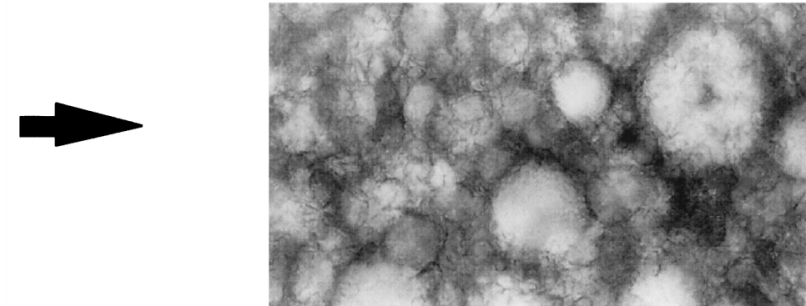

(b) after 7days

$\overline{20 \mu \mathrm{m}}$

Fused mixture : $5 \% \quad \beta-C y D(w / w), 1 \%$ Minocycline Hydrochloride Ointment base : $\mathrm{HO} 70$ : PL 30

Stored at room temperature

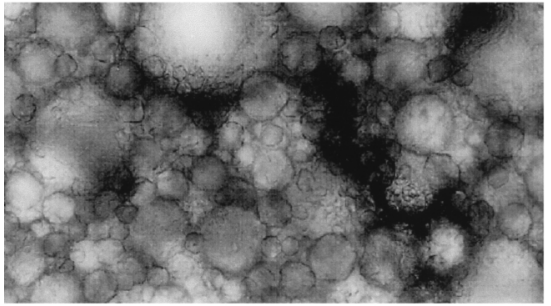

(a) before storage

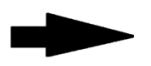

Fused mixture : $5 \% \quad \beta$-CyD (w/w), 1\% Minocycline Hydrochloride

Ointment base : $\mathrm{HO} 70$ : PL 30

Storage temperature : $5^{\circ} \mathrm{C}$

Fig. 10. Photomicrographs of (a) freshly Prepared Ointment and (b) Stored Ointment for 7d

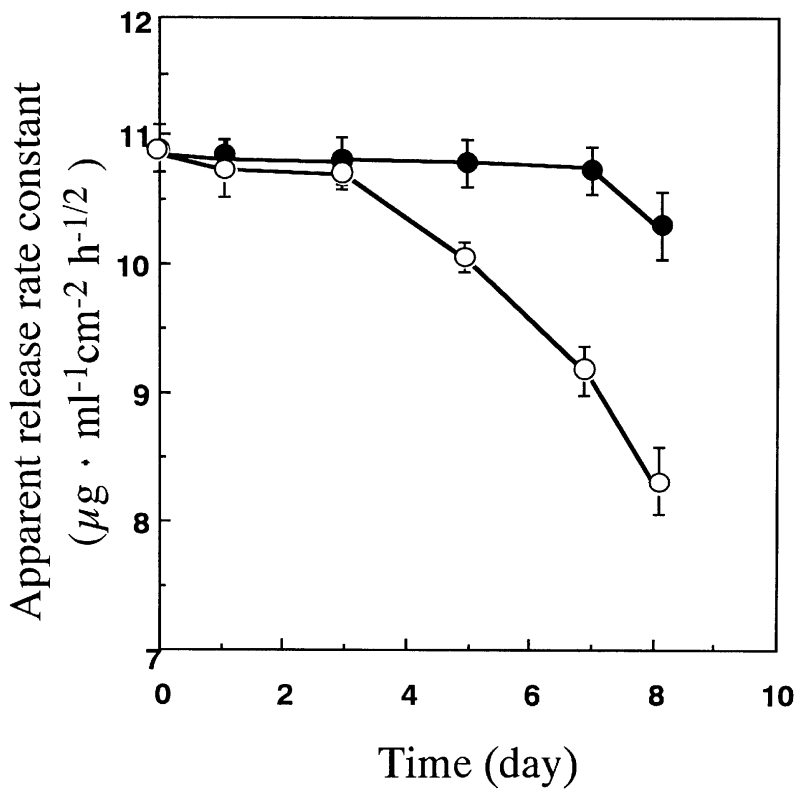

Fig. 11. Changes in Apparent Release Rate Constant of Fused Ointments with $\beta-\mathrm{CyD}$ during Storage

Storage temperature: $0: 5^{\circ} \mathrm{C}, \bigcirc:$ room temperature. Data represent the mean \pm S.E. of three experiments.

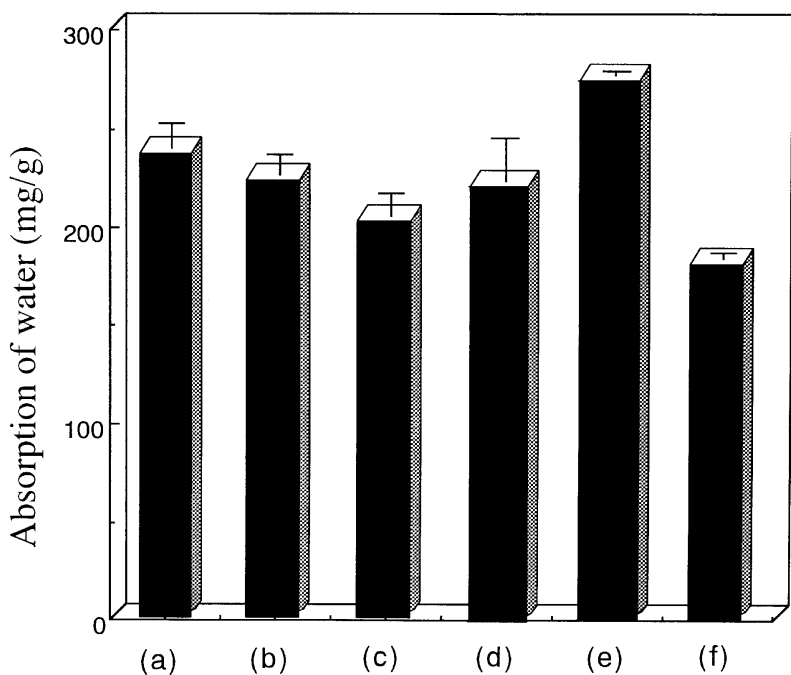

Fig. 12. Effect of Addition of Hydrophobically Modified Hydroxypropyl Methylcellulose on Absorption of Water (a) HM-Hydroxypropyl methylcellulose (T-5059), (b) HM-Hydroxypropyl methylcellulose (T-5060), (c) HM-Hydroxypropyl methylcellulose (T-5061), (d) HM-Hydroxypropyl methyl cellulose (T-5062), (e) Hydroxypropyl cellulose, (f) None, Data represent the mean \pm S.E. of three experiments. 


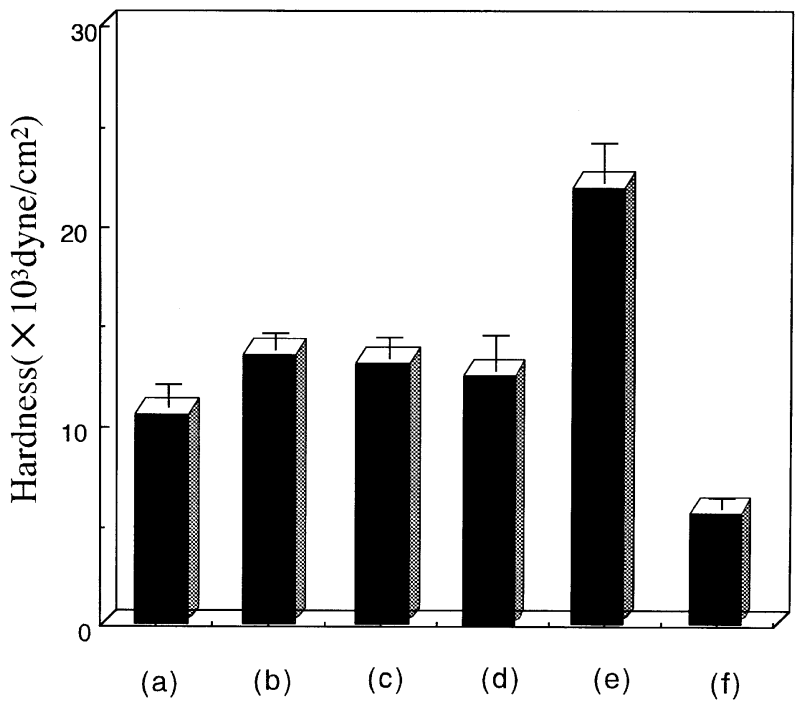

Fig. 13. Effect of Type of Hydrophobically Modified Hydroxypropyl Methylcellulose on the Hardness of Macrogol Ointment Base

(a) HM-Hydroxypropyl methylcellulose (T-5059), (b) HM-Hydroxypropyl methylcellulose (T-5060), (c) HM-Hydroxypropyl methylcellulose (T-5061), (d) HM-Hydroxypropyl methylcellulose (T-5062), (e) Hydroxypropyl cellulose, (f) None. Data represent the mean \pm S.E. of three experiments.

放出性は，回転ディスク法を用いて評価を行った. その結果, Fig. 14 に示すごとく各種 HM-HPMC 添加 $\mathrm{MO}$ 基剤で $50 \%$ 薬物溶出時間 $\left(T_{50}\right)$ を約 22 分までにしか延長することができず，HM-HPMC 単独では薬物の放出を徐放化することができなかつ た。 そこで，新たな処方設計の検討を行った。

\section{4-2. CP 及び HM-HPMC 添加 MO 基剤の特性} 今回, HM-HPMC の 4 種類のサンプルのうち, LA 基の置換度が最も大きい $\mathrm{T}-5062$ を選択した。 MO に HM-HPMC (T-5062) と，CP を種々の割 合で添加し調製した軟膏基剤からの薬物放出試験 を，回転ディスク法にて評価を行った． Figure 15 に示すように HM-HPMC にCP を種々の割合で混 合し, MO に添加することによりゲル形成能力を高 め, HM-HPMC : $\mathrm{CP}=3: 7$ の処方において $T_{50}$ を 約 171 分にまで遅延化することができた.これは, 今まで報告してきた中で最も徐放化能力に優れた $\mathrm{HPC}: \mathrm{CP}=3: 7$ 添加 $\mathrm{MO}$ 処方基剂 $\left(T_{50}=\right.$ 約 90 分 $)$ よりはるかに優れた徐放機能であった。また， $\mathrm{HPC}$ : CP の濃度比を変化させることにより， $T_{50}$ をコントロールできることが明らかとなった。 上記 の薬物放出機構は, 軟膏基剤中の HM-HPMC 及び

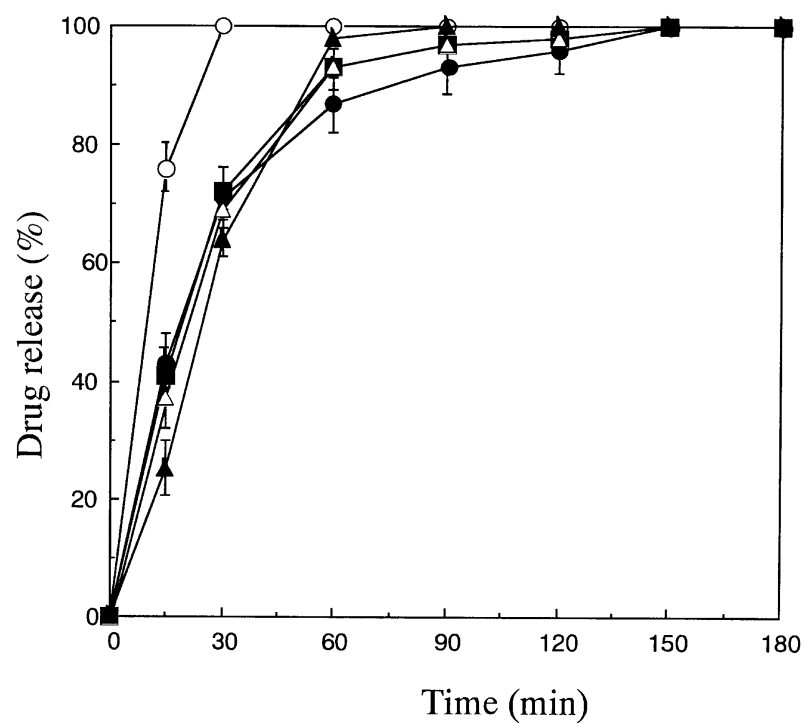

Fig. 14. Release Behavior of Minocycline Hydrochloride from Macrogol Ointment Containing Various Content of Hydrophobically Modified Hydroxypropyl Methylcellulose $\mathrm{O}:$ None $+\mathrm{MO}$, : $5 \% \mathrm{HM}$-Hydroxypropyl methylcellulose (T5059) + MO, ם : 5\% HM-Hydroxypropyl methylcellulose (T-5060) + MO, $\triangle: 5 \%$ HM-Hydroxypropyl methylcellulose (T-5061) +MO, $\boldsymbol{\Delta}: 5$ $\%$ HM-Hydroxypropyl methylcellulose (T-5062) + MO. Data represent the mean \pm S.E. of three experiments.

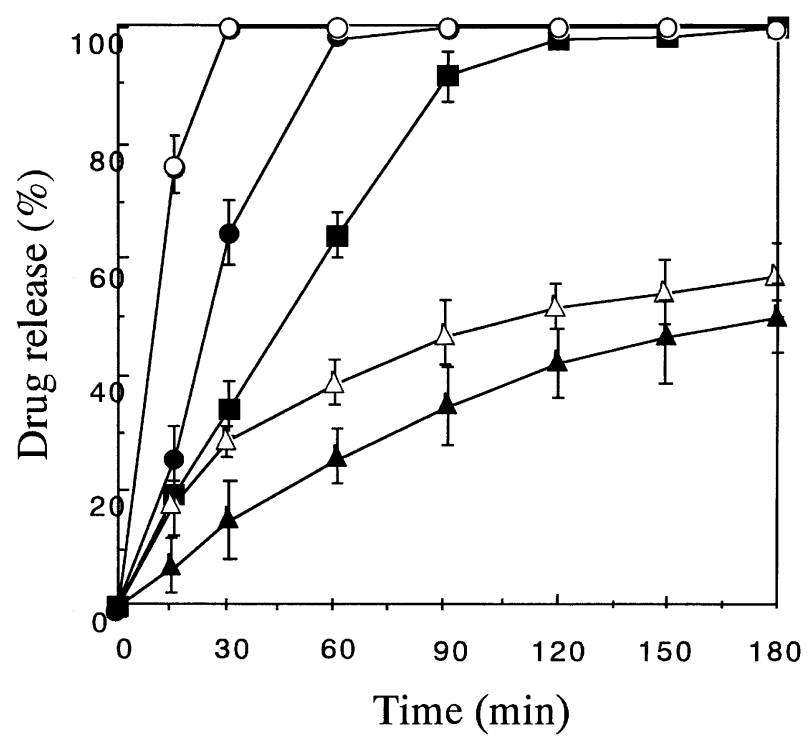

Fig. 15. Effect of the Composition Ratio of HM-HPMC: CP on the Release of Minocycline Hydrochloride from Ointment

O : None, 1 : HM-HPMC (T-5062): CP10:0, घ : HM-HPMC (T $-5062):$ CP5 : $5, \triangle:$ HM-HPMC (T-5062): CP4 : 6, $\boldsymbol{\Delta}:$ HM-HPMC (T $-5062)$ : CP3 : 7. Data represent the mean \pm S.E. of three experiments.

$\mathrm{CP}$ が迅速に水分を吸収して膨潤してゲル層を形成 した後，薬物がこのゲル層を拡散しながらゲルの溶 解とともに徐々に放出されるものと考えられる. 薬 物放出試験の結果から，薬物の水に対する放出は 
$\mathrm{CP}$ 含量の増大に伴い遅延する傾向を示した。これ は CP 含量が多いほど吸水が速く, ゲル層の溶解が 遅くなったためと思われる。また，同量の CP 含量 でHPCより HM-HPMC を添加した方が溶出が遅 延したのは，後者が前者より疎水性の高いゲル層を 形成したためと推定された。

Figure 16(a)は MO に HM-HPMC (T-5062) と $\mathrm{CP}$ を各種割合で添加した軟膏基剂の吸水性を検討 した結果である。吸水量は，HM-HPMC 添加 MO 基剤 $1 \mathrm{~g}$ あたりの量を示している. CP の割合が増 加するにつれて吸水性が高くなることが判明した.

$\mathrm{HPC}-\mathrm{CP}$ 添加 $\mathrm{MO}$ 基剤と比較してみると, $t$-検定 により $\mathrm{HM}-\mathrm{HPMC}$ 添加 MO 基剤と HPC-CP 添加 $\mathrm{MO}$ 基剤の両者には，吸水力において有意差がな く，良好な吸水力を有していると判断された.

Figure 16(b) はこれら軟膏基剤の硬度を検討した 結果である．CP の割合が増加するにつれて硬度が 高くなり，硬い基剤になることが判明した，HPC$\mathrm{CP}$ 添加 MO 基剂と比較してみると, $t$-検定により $\mathrm{HM}-\mathrm{HPMC}$ 添加 MO 基剂と HPC-CP 添加 MO 基 剂の両者には, 固さにおいても有意差がなく, 臨床 使用上は問題のない硬度であることが明らかとなつ た. ${ }^{23)}$

\section{4-3. 軟膏基剤の硬度と薬物放出速度薬物の} 溶出は基剤の溶解とともに起こる，水溶性高分子を 添加することにより, 薬物溶出が遅延する理由は, 軟膏基剂中で水溶性高分子が水分を吸水し膨潤した 後，基剂内で徐々に溶解しゲル層を形成する現象と 密接に関係する．このゲル層は薬物の基剤中の拡散
を押さえるとともに, 基剤の溶解速度を低下させ る.これらの効果により, 薬物の溶出速度は抑制さ れる。したがって, 基剤硬度が高くなるほど薬物溶 出は遅くなると考えられる. Figure 17 には，今ま でに我々が調製した種々の水溶性高分子添加 MO 基剤について, 硬度及び薬物放出時間との相関関係 をプロットした。 今回, 報告した HM-HPMC : $\mathrm{CP}=3: 7$ 添加の処方は, 以前に報告した $\mathrm{HPC}$ : $\mathrm{CP}=3: 7$ 添加の処方と同様, $\mathrm{CP}$ 単独添加の場合

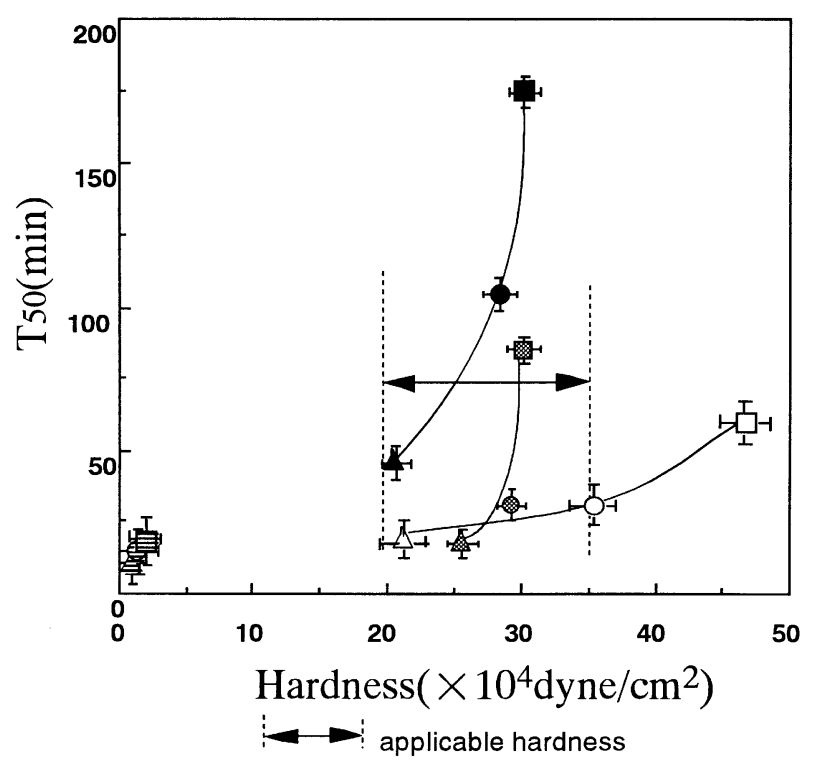

Fig. 17. Relationship between Drug Release Rate and Hardness of Macrogol Ointment

$\boldsymbol{\Delta}:$ HM-HPMC5 : CP5, ○: HM-HPMC4: CP6, ■ : HMHPMC $3:$ CP7, $\triangle: 3 \% \mathrm{CP}, \bigcirc: 4 \% \mathrm{CP}, \quad \square: 5 \% \mathrm{CP}, \triangleq: 3 \% \mathrm{HM}-$

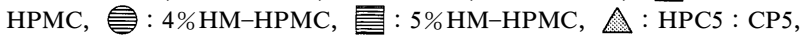
O : HPC4 : CP6, $2:$ HPC3 : CP7. Data represent the mean \pm S.E. of three experiments. (a)

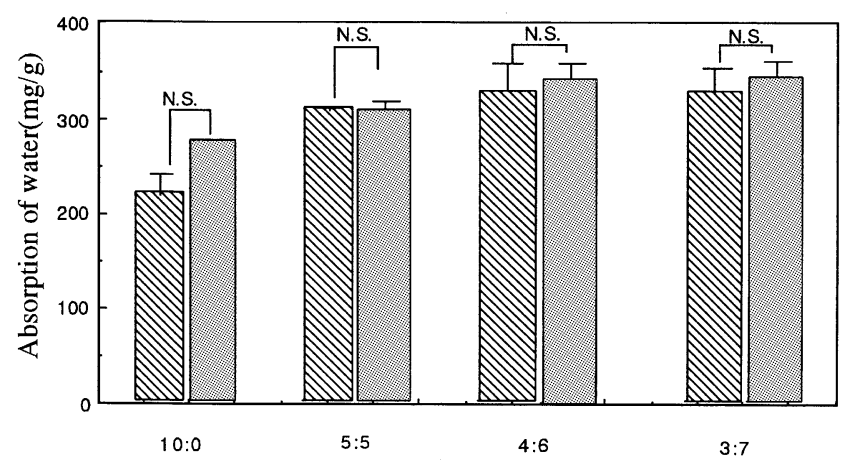

(b)

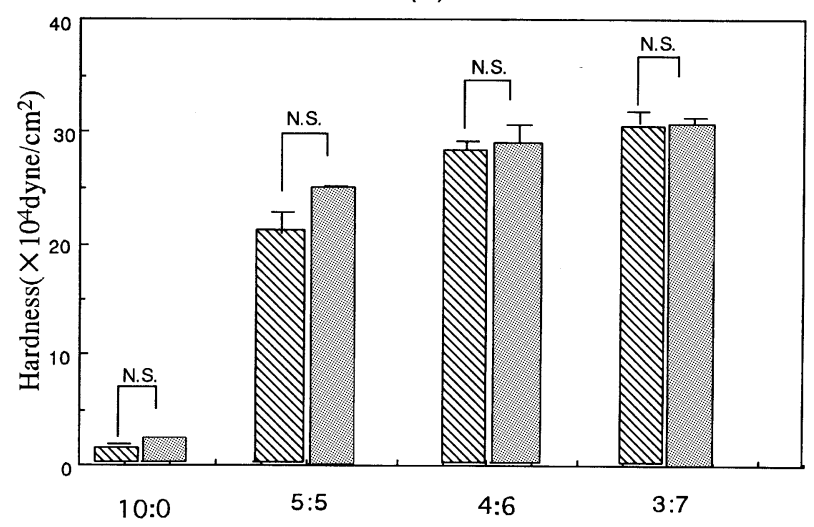

Fig. 16. Effect of the Composition Ratio of HM-HPMC: CP and HPC: CP on the Absorption of Water (a) and on the Hardness (b) : HM-HPMC (T-5062): CP, : HPC: CP. Data represent the mean \pm S.E. of three experiments. 
Table 4. Healing Index of the Treatment with Alteration of Ointment Base according to the Stage of Bedsore and Conventional Treatment

\begin{tabular}{ccccc}
\hline \hline Grade & $\mathrm{II}^{a)}$ & $\mathrm{III}^{b)}$ & \multicolumn{1}{c}{$\mathrm{IV}^{c)}$} & \multicolumn{1}{c}{$\mathrm{V}^{d)}$} \\
\hline$(1)$ & $0.04 \pm 0.01$ & $0.15 \pm 0.10$ & $0.14 \pm 0.03$ & $0.07 \pm 0.08$ \\
$(2)$ & $0.17 \pm 0.02^{*}$ & $0.21 \pm 0.11$ & $0.31 \pm 0.06^{* *}$ & $0.25 \pm 0.17^{* *}$ \\
\hline
\end{tabular}

(1): conventional treatment, (2): treatment with alteration of ointment base according to the stage of bedsore. a) $n=2, b) n=2$, c) $n=4, d) n=3$. *: $<0.05$ vs conventional treatment, ${ }^{*}:<0.01$ vs conventional treatment.

より適切な硬度を保ちながら薬物溶出速度を制御し ていることが明らかである. HM-HPMC 単独の水 の進入速度係数は $0.65 \mathrm{ml} / \mathrm{min}$ と小さいが, CP の 存在により吸水速度が改善され，速やかにゲルを形 成し, HM-HPMC の疎水性が影響し溶出性を制御 したものと推定された. また, HM-HPMC : CP= $3: 7$ 添加系の吸水時の硬度は, HM-HPMC ゲルの 存在により軟化し，経験的な適正軟膏強度（Fig. 17）の範疇となった.

\section{5. 各種軟亳基剤の病期別選択による裖瘡治療成} 績の向上

5-1. 治療成績 イソジンシュガーゲルを使用 し画一的治療を行った 11 症例と, 各種軟膏基剤の 病期を重視した病期別使い分け治療（筆者らが開発 した, 感染期, 壊死付着期, 肉芽増殖期, 上皮形成 期に適した軟膏基剂を臨床使用）を行つた 11 症例 計 22 症例において, 治療効果の比較検討を行った.

Cambel の分類による grade 別症例数は, 各々 grade II 2 症例, grade III 2 症例, grade IV 4 症例, grade V 3 症例であった. Healing index による治療 効果比較は, Table 4 に示すように grade IV ・ grade $\mathrm{V}$ と言う難治性の裖瘡において, 各種軟膏基剤の病 期を重視した病期別使い分け治療を行った症例の方 が，イソジンシュガーゲルを使用し画一的治療を行 つた症例よりも治療効果が有意 $(p<0.01)$ に高い ことが判明した。 また, grade II の症例に対して も, 治療効果が有意 $(p<0.05)$ に高かった.

\section{6. おわりに}

裖瘡の病期に対して製剂設計した最適な基剤をそ れぞれ選択し，特に肉芽増殖期，上皮形成期に対し ては湿潤環境を保つゲル化軟膏基剤を使用し，高山 赤十字病院において病期別治療を行った．従来の画 一的に感染期, 壊死付着期, 肉芽増殖期, 上皮形成 期に対してイソジンシュガーゲル及び油脂性基剤に 抗生物質を添加した軟膏を局所的に投与を行ってき
た治療法と比較検討し，筆者が開発した軟膏基剤の 優位性を確認した. イソジンシュガーゲルを使用し 画一的治療を行った 11 症例と, 各種軟膏基剤の病 期を重視した病期別使い分け治療を行った 11 症例 計 22 症例において, 治療効果の比較検討を行っ た.その結果, grade IV ・ grade V という難治性の 裖瘡において, 各種軟膏基剂の病期を重視した病期 別使い分け治療を行った症例の方が, イソジンシュ ガーゲルを使用し，画一的治療を行つた症例よりも 治療効果が優れていることが判明した。これは, 裖 瘡の病期に対して最適な基剂をそれぞれ選択し，木 目の細やかな治療を行ったことと, さらに肉芽増殖 期, 上皮形成期に対しては湿潤環境を保つ基剤を使 用し, 肉芽組織の増殖と創収縮の促進を行つた結果 であると考えられる. したがって, これらの結果か らも我々が開発した補瘡のそれぞれの病期に使用し た軟膏基剤は, 裖瘡治療に有効であることが示唆さ れた。

\section{謝辞本研究に際し, 終始御㴧篤なる御指導御} 鞭撻を賜りました岐阜薬科大学製剤学研究室川島嘉 明教授に深く感謝いたします。また多くの貴重なご 助言を賜りました同, 竹内洋文助教授, 山本浩充助 手, 徳島大学薬学部日野知証助教授に厚くお礼申し 上げます，さらに, 終始有益なご指導と御協力を頂 きました，ファイザー製薬丹羽敏幸博士，日本たば こ株式会社芹ヶ野孝則博士, 山之内製薬保地毅彦博 士に感謝いたします。

\section{REFERENCES}

1) Kawai S., Acta Dermatol., 89, 693-714 (1994).

2) Takehara K., Sannomiya F., Med. Drug J., 30, 1853-1855 (1994).

3) Victoria M. D., Roberta J. M., Matsuoka J., 
Gary R. G., Surg., 112, 18-23 (1992).

4) Matsuoka J., Gary R. G., Proc. Natl. Acad. Sci. U.S.A., 86, 4416-4420 (1989).

5) Shigemoto Y., Yoshioka Y., Matsuoka T., $J$. of New Reme. Clin., 33, 454-459 (1984).

6) Hori Y., J. New Reme. Clin., 34, 846-848 (1985) .

7) Tanoue H., Tanida Y., Kumasaka W., Hashimoto I., J. Clin. Ther. Med., 6, 24692479 (1990).

8) Izumi Y., Honda M., Watanabe H., Hatano M., Gendai Iryo, 15, 161-165 (1983).

9) Iida H., Ishiguro S., Ito H., Orthop. Traum. Surg., 42, 709-712 (1999).

10) Nohara N., Nishinihon J. Derm., 46, 582-591 (1983).

11) Fukuda K., Diag. Treat., 72, 175-180 (1983).

12) Sawada K., Surg. Diag. Treat., 18, 1117-1120 (1984).

13) Sawada K., Edamatsu M., Ikegami S., Surg. Diag. Treat., 10, 694-698 (1984).

14) Sone K., Nakamura Y., Ikeda T., Hanada Y., Jpn. J. Hosp. Pharm., 10, 315-322 (1984) .

15) Miyachi Y., Imamura S., Med. Drug J., 26, 43
-48 (1990).

16) Shigeyama M., Ohgaya T., Kawashima Y., Takeuchi H., Hino T., Chem. Pharm. Bull., 47, 744-748 (1999).

17) Shigeyama M., Ohgaya T., Kawashima Y., Takeuchi H., Hino T., Chem. Pharm. Bull., 48, 617-622 (2000).

18) Shigeyama M., Ohgaya T., Kawashima Y., Takeuchi H., Hino T., Chem. Pharm. Bull., 49, 129-133 (2001).

19) Shigeyama M., Ohgaya T., Kawashima Y., Takeuchi H., Yakuzaigaku, 60, 253-260 (2000) .

20) Higuchi W. I., Higuchi T., J. Am. Pharm. Assoc., 49, 598-606 (1960).

21) Higuchi W. I., Pharm. Sci., 51, 802-806 (1962).

22) Higuchi T., J. Soc. Cosmetic Chemists, 11, 85 -97 (1960).

23) Shigeyama M., Ohgaya T., Yoneyama T., Futamura M., Murakawa K., Shibata H., Kawashima Y., Takeuchi H., Yakugaku Zasshi, 121, 441-450 (2001). 